\title{
Mesenchymal Stem Cells Isolated from the Anterior Cruciate Ligament: Characterization and Comparison of Cells from Young and Old Donors
}

\author{
Patrick Prager, $\mathrm{MD}^{1}$, Manuela Kunz ${ }^{1}$, Regina Ebert, $\mathrm{PhD}^{1}$, Ludger Klein-Hitpass, $\mathrm{PhD}^{2}$, Jakob Sieker, $\mathrm{MD}^{3}$, \\ Thomas Barthel, $\mathrm{MD}^{1}$, Franz Jakob, $\mathrm{MD}^{1}$, Christian Konrads, $\mathrm{MD}^{1,4, *}$, and Andre Steinert, $\mathrm{MD}^{1,5, *}$ \\ ${ }^{1}$ Department of Orthopaedic Surgery, Koenig-Ludwig-Haus, Center for Musculoskeletal Research, Julius-Maximilians-University Wuerzburg, Wuerzburg; ${ }^{2}$ BioChip \\ Laboratory, Center for Medical Biotechnology, University of Duisburg-Essen, Essen, Germany; ${ }^{3}$ Department of Orthopaedic Surgery, Harvard Medical School, Boston, \\ MA, USA; ${ }^{4}$ Department of Orthopaedic Trauma, Center for Trauma Research, BG Trauma Center Tuebingen, University of Tuebingen, Tuebingen; ${ }^{5}$ Department of \\ Orthopaedics and Traumatology, Agatharied Hospital, Teaching Hospital of the University of Munich, Hausham, Germany
}

\begin{abstract}
Purpose: Mesenchymal stem cells (MSCs) isolated from the anterior cruciate ligament (ACL) share multiple characteristics of bone marrow-derived mesenchymal stem cells (BMSCs), allowing their use for regenerative therapies. Injuries to the ACL can affect people of all ages. This study assesses whether the regenerative potential of ACL-derived MSCs (ACL-MSCs) from old donors is as high as the potential of ACL-MSCs from young donors. Materials and Methods: ACL-MSCs were isolated from ACL tissues obtained from young and old donors at the time of ACL reconstruction or arthroplasty. Proliferative capacity, multilineage differentiation potential (chondrogenic, osteogenic, and adipogenic lineages), and transcriptome-wide gene expression were assessed and compared between young and old donors. BMSCs of middle-aged donors served as an additional comparator. Results: No substantial differences between ACL-MSCs from young and old donors were observed in their proliferative capacity and multilineage differentiation potential. The latter did not substantially differ between both ACL-MSC groups and BMSCs. Differential expression of genes related to the cytoskeleton and to protein dephosphorylation amongst other pathways was detected between ACL-MSCs from young and old donors.

Conclusions: Regenerative potential of ACL-MSCs from old donors was not substantially lower than that from young donors, suggesting that regenerative therapies of ACL tears are feasible in both age groups. In vivo studies of the effect of age on the efficacy of such therapies are needed.
\end{abstract}

Keywords: Knee, Anterior cruciate ligament, Stem cell, Differentiation, Donor age

Received August 29, 2017; Revised (1st) November 2, 2017;

(2nd) November 26, 2017; Accepted December 16, 2017

Correspondence to: Christian Konrads, MD

Department of Orthopaedic Surgery, Koenig-Ludwig-Haus, Center for Musculoskeletal Research, Julius-Maximilians-University Wuerzburg, Wuerzburg, Germany

Tel: +49-931-803-3136, Fax: +49-931-903-1209

E-mail: christian.konrads@gmail.com

Source of funding: This study was supported by the Bayerische Forschungsstiftung and the publication was funded by the German Research Foundation (DFG) and the University of Wuerzburg in the funding programme Open Access Publishing.

*These authors contributed equally to this study.

This is an Open Access article distributed under the terms of the Creative Commons Attribution Non-Commercial License (http://creativecommons.org/licenses/by-nc/4.0/) which permits unrestricted non-commercial use, distribution, and reproduction in any medium, provided the original work is properly cited.

\section{Introduction}

A tear of the anterior cruciate ligament (ACL) is a common injury, which often requires surgical reconstruction using an autologous tendon graft, e.g., the semitendinosus tendon ${ }^{1)}$. In general, successful ligament healing is achieved when the sequence of blood clot formation, invasion by leukocytes and fibroblasts, proliferation, extracellular matrix (ECM) molecule secretion, and tissue remodeling take place without disturbances ${ }^{2}$. Following an ACL injury, the high intra-articular activation of the fibrinolytic system disintegrates the blood clot too early to allow for invasion and ECM production of cells; and thereby permanently impedes successful healing ${ }^{3)}$.

When untreated, tears of the ACL can result in severe joint instability and facilitate the development of secondary meniscal tears and osteoarthritis, which necessitates the functional restoration 
of the ligament ${ }^{4}$. ACL reconstruction, the surgical replacement of the torn ligament by an autologous tendon graft (e.g., semitendinosus or patella tendon) is the current standard treatment ${ }^{5}$. Recent high level evidence suggests that current techniques of ACL reconstruction do not substantially improve patient-reported outcomes ${ }^{6}$. On average, patients that received joint surgery due to an ACL injury are subject to total knee replacement 15 years earlier than those with previous knee surgery not related to an ACL injury ${ }^{7}$. In order to improve outcomes after an ACL injury, novel regenerative therapies are being explored, which might allow restoration of the proprioceptive nerve functions of the native ACL obviating the harvest of an autologous tendon graft.

Tissue engineering approaches for the restoration of the ACL have been described, many of which use multipotent mesenchymal stem cells (MSCs) for several reasons. MSCs have been isolated from a variety of different tissues such as bone marrow, adipose tissue, trabecular bone, and tendon ${ }^{8}$. Research showed that cells isolated from torn ACLs of young donors possess a surface antigen expression profile highly similar to that of bone marrow-derived mesenchymal stem cells (BMSCs) and they were able to undergo multilineage differentiation, which qualifies them as MSC types" ${ }^{9}$. Thus, the use of ACL-derived MSCs (ACL-MSCs) for regenerative therapies of the injured ACL appears attractive. However, several studies have reported age-dependent differences in the regenerative capacities of BMSCs of differently aged donors ${ }^{10}$. Since injuries to the ACL can occur at both young and old age, it is necessary to define whether such regenerative approaches can be beneficial to both age groups. The objective of this study was to assess whether the regenerative potential of ACL-MSCs from old donors ( $>60$ years) is as high as the potential of ACL-MSCs from young donors ( $<30$ years). We specifically tested the hypothesis that ACL-MSCs from old and young donors would be different regarding transcriptome-wide gene expression, proliferative capacity (colony forming unit [CFU] assay, cumulative population doubling times), and multilineage differentiation potential (chondrogenic, osteogenic, and adipogenic lineages). BMSCs of middle-aged donors served as an additional comparator in the cell culture assays.

\section{Materials and Methods}

This study was approved by our University's Ethics Committee. Informed consent was obtained from all individual participants included in the study.

\section{Patient Characteristics and Tissue Collection}

ACL tissue was obtained from 5 young (23.2 years; range, 17 to
27 years) and 6 old ( 73.7 years; range, 69 to 79 years) ACL donors at the time of ACL reconstruction or joint replacement surgery.

\section{Isolation and Culture of ACL-MSCs}

ACL-MSCs were isolated using collagenase digestion" ${ }^{9)}$. Tissue specimens were minced into smaller pieces and digested in 12.5 $\mathrm{U} / \mu \mathrm{L}$ collagenase NB4 (Serva Electrophoresis GmbH, Heidelberg, Germany) in complete medium consisting of Dulbecco's Modified Eagle Medium (DMEM)/Ham's F12 (PAA Laboratories GmbH, Coelbe, Germany), 10\% fetal bovine serum (FBS, PAA Laboratories $\mathrm{GmbH}$ ), 1\% penicillin/streptomycin (PAA Laboratories $\mathrm{GmbH}$ ) and $50 \mathrm{mg} / \mathrm{mL}$ L-ascorbic acid 2-phosphate (Sigma Aldrich GmbH, Taufkirchen, Germany) for 18 hours. The released cells were separated from tissue debris using a cell strainer, pelleted at 1,200 g for 5 minutes, re-suspended in complete medium, and seeded in $75 \mathrm{~cm}^{2}$ flasks. For all subsequent differentiation protocols, cells were cultivated in an incubator at $37^{\circ} \mathrm{C}$ and $5 \% \mathrm{CO}_{2}$ in a humidified atmosphere with media changes every 2-3 days. Cells were passaged using 1\% trypsin (PAA Laboratories $\mathrm{GmbH}$ ) for 5 minutes for detachment, an equal volume of complete medium to stop the reaction, centrifugation at $1,200 \mathrm{~g}$ for 5 minutes to pellet cells, and resuspension in complete medium, after which the cells were seeded at a minimal density of $5 \times 10^{3}$ per $\mathrm{ml}$ in cell culture flasks.

\section{Isolation and Culture of Human BMSCs}

BMSCs were isolated from 3 donors undergoing total hip replacement surgery (mean age 50 years). Trabecular bone was harvested from the femoral diaphysis and transferred to $50 \mathrm{~mL}$ canonical tubes containing $20 \mathrm{~mL}$ complete medium, vortexed and centrifuged at $1,200 \mathrm{~g}$ for 5 minutes. The fatty supernatant was carefully removed and pelleted cells were washed for five times in fresh complete medium. The washing medium was collected, vortexed, and separated from remaining bony fragments using a cell strainer. Following centrifugation at 1,200 g for 5 minutes, the cells were re-suspended in complete medium and plated at a density of at least $10^{6}$ cells per $\mathrm{mL}$ in complete medium in $175 \mathrm{~cm}^{2}$ flasks. After three days, the adherent MSCs were washed with pre-warmed phosphate buffer solution to remove non-adherent blood cells from the flasks. Subsequent culture was performed similarly to the culture of ACL-MSCs.

\section{Colony Forming Units-Fibroblasts Assay}

A modified protocol of the CFU-fibroblasts (CFU-f) assay was used $^{11)}$. First passage ACL-MSCs were seeded at a density of 200 cells per $\mathrm{cm}^{2}$ in complete medium in 6 well plates. Medium was 
changed every 2-3 days for a total time of 10 days followed by the fixation of the cell layer with cold methanol for 10 minutes. CFU$\mathrm{f}$ colonies were detected by crystal violet staining for 5 minutes followed by three washing steps with phosphate buffer solution. The colonies were counted manually by four independent observers with an accumulation of at least 25 cells being counted as a single colony.

\section{Cumulative Population Doublings}

Cumulative population doublings were investigated in a longterm culture system. Therefore, third passage cells were seeded at a density of $5 \times 10^{3}$ cells per $\mathrm{cm}^{2}$ in three $25 \mathrm{~cm}^{2}$ cell culture flasks for each cell donor and cultured in $5 \mathrm{~mL}$ complete medium. Once the monolayer became subconfluent, the cells were detached from the flasks using trypsin digestion, counted, and reseeded as described above. The procedure was repeated until no repeated increase in cell number could be detected or until a total time of 100 days in culture.

\section{Chondrogenic Differentiation}

Chondrogenic differentiation was performed in a pellet culture system, as previously described ${ }^{12}$. Third passage cells were detached from the plastic surface of culture flasks using a trypsin digestion and counted, and $2.5 \times 10^{5}$ cells were transferred in 50 $\mathrm{mL}$ canonical tubes containing $500 \mu \mathrm{L}$ of either chondrogenic or control media, followed by centrifugation at 1,500 g. Pellets were cultured in DMEM high glucose medium supplemented with $1 \%$ penicillin/streptomycin, $40 \mathrm{ng} / \mathrm{mL}$ L-proline, $50 \mathrm{ng} / \mathrm{mL}$ L-ascorbic acid 2-phosphate sesquimagnesium salt hydrate, 100 $\mathrm{ng} / \mathrm{mL}$ pyruvate, $100 \mathrm{nM}$ dexamethasone, $1 \%$ ITS (all Sigma-Aldrich, Schnelldorf, Germany), and human transforming growth factor (TGF)- $\beta 1$ (R\&D Systems) for 28 days with the caps slightly opened to enable gas exchange. Control pellets were cultured in the absence of TGF- $\beta 1$. Reverse transcription polymerase chain reaction (RT-PCR) of the chondrocyte-specific marker genes aggrecan core protein $(A C A N)$, byglican $(B G N)$, collagen alpha-1(II) chain (COL2A1), cartilage oligomeric matrix protein $(C O M P)$, and fibromodulin (FMOD) were used to gauge the degree of chondrogenic differentiation. Collagen alpha- $1(\mathrm{X})$ chain (COL10A1) was used to determine the degree of chondrocyte hypertrophy. Glycosaminoglycan (GAG) deposition was quantified using the Blyscan Glycosaminoglycan Assay kit (Tebu-bio, Offenbach, Germany) and histomorphometric quantification of alcian blue positive areas. Further, qualitative type II collagen immunohistochemistry was performed.

\section{Osteogenic Differentiation}

Osteogenic differentiation was performed in a monolayer culture system as previously described with slight modifications ${ }^{12)}$. Confluent passage four donor cells were cultured in DMEM high glucose medium containing $10 \%$ FBS, $1 \%$ penicillin/streptomycin, $10 \mathrm{ng} / \mathrm{mL}$ bone morphogenetic protein-2 (kindly provided by Prof. Dr. Walter Sebald, Emeritus Chair of Physiological Chemistry, Faculty of Medicine, University of Wuerzburg, Germany), 10 $\mathrm{mM} \beta$-glycerophosphate, $50 \mathrm{ng} / \mathrm{mL}$ L-ascorbic acid 2-phosphate sesquimagnesium salt hydrate, and $100 \mathrm{nM}$ dexamethasone (all Sigma Aldrich $\mathrm{GmbH}$ ) for 28 days. Control cells were cultured in DMEM high glucose containing 10\% FBS and 1\% penicillin/ streptomycin only. RT-PCR of the osteocyte-specific marker gene alkaline phosphatase, tissue-nonspecific isozyme $(A L P L)$ and histomorphometric quantification of alkaline phosphatase $(A L P)$ and alizarin red positive areas were performed to gauge the degree of osteogenic differentiation.

\section{Adipogenic Differentiation}

Adipogenic differentiation was performed in a monolayer culture system according to a modified protocol described before ${ }^{12}$. Therefore, confluent fourth passage cells were incubated with DMEM high glucose containing 10\% FBS, 1\% penicillin/ streptomycin, $1 \mu \mathrm{g} / \mathrm{mL}$ insulin, $100 \mu \mathrm{M}$ indomethacin, $0.5 \mathrm{mM}$ 3-isobutyl-1-methylxanthine, and $1 \mu \mathrm{M}$ dexamethasone (all Sigma Aldrich $\mathrm{GmbH}$ ) for a total time of 21 days. Control cells were cultured in DMEM high glucose containing 10\% FBS and 1\% penicillin/streptomycin only. RT-PCR of the adipocyte-specific marker genes lipoprotein lipase (LPL) and peroxisome proliferator-activated receptor $\gamma(P P A R G)$, as well as the histomorphometric quantification of oil red $\mathrm{O}$ positive areas were performed to gauge the degree of adipogenic differentiation.

\section{RNA Isolation and RT-PCR}

RNA from ACL-derived cells was isolated using the NucleoSpin RNA II kit (Machery-Nagel GmbH, Dueren, Germany) according to the manufacturer's instructions. The pellets of chondrogenic cultures were previously homogenized in the first buffer of the respective kit using a pestle. Then, $1 \mu \mathrm{g}$ of isolated RNA was transcribed into cDNA using the BioScript kit (Bioline GmbH, Luckenwalde, Germany) with random hexamer primers (Life Technologies GmbH, Darmstadt, Germany) according to the manufacturer's protocols. Gene expression was analyzed using RT-PCR with reaction mixtures containing $3 \mu \mathrm{L} 10 \times$ reaction buffer (shipped with the MangoTaq from Bioline $\mathrm{GmbH}$ ), $1 \mu \mathrm{L}$ $10 \mathrm{mM}$ dNTP mixture (Bioline $\mathrm{GmbH}$ ), $1 \mu \mathrm{L}$ of each forward 
Table 1. Primers and Polymerase Chain Reaction Conditions

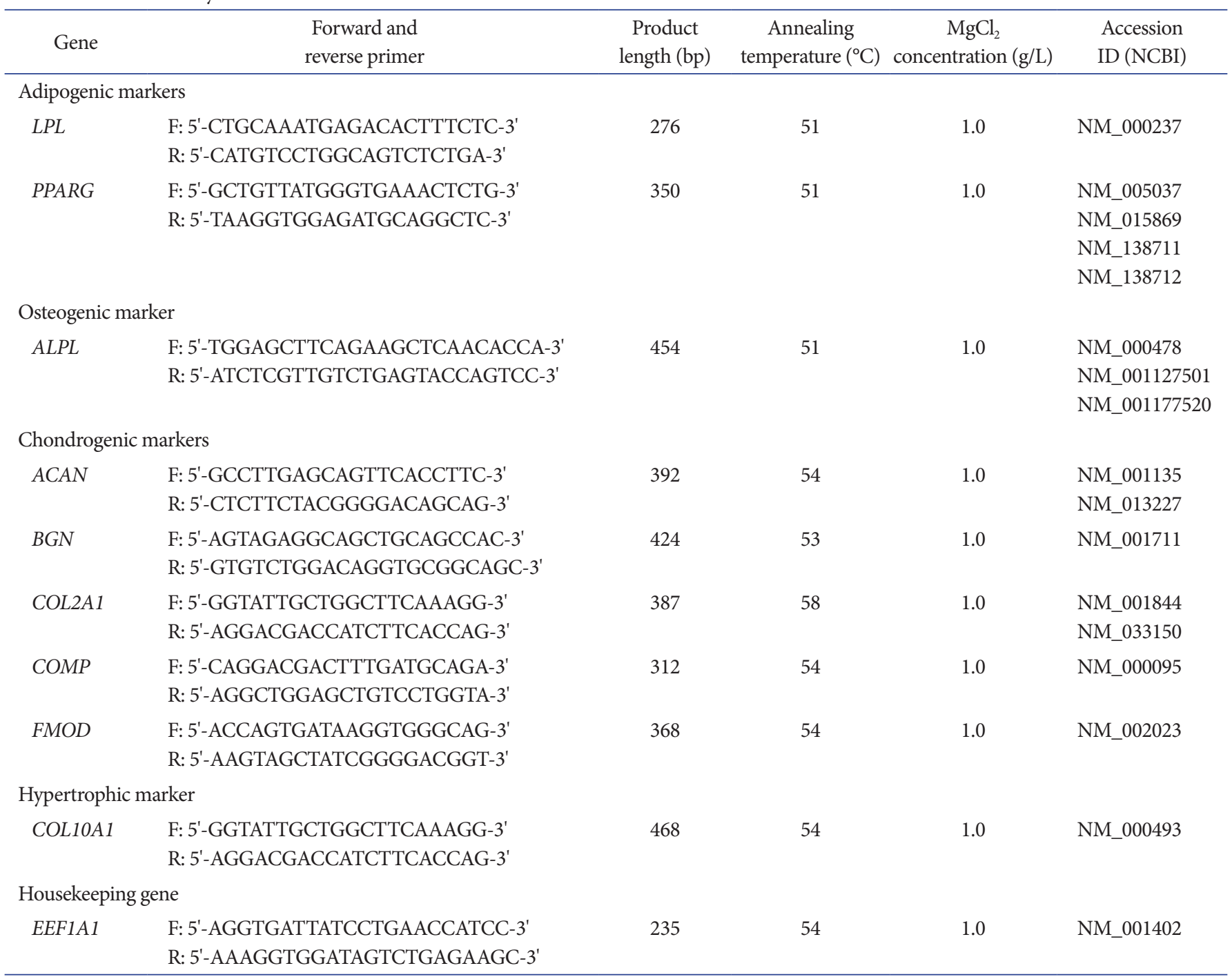

Forward and reverse primers to amplify specific gene products along with their associated product lengths $\left(\mathrm{l}_{\text {Amplicon }}\right)$, the annealing temperature $\left(\mathrm{T}_{\text {Anneal }}\right)$, the concentrations of $\mathrm{MgCl}_{2}$ used in the reaction mixture $\left(\mathrm{c}_{\mathrm{MgCl}}\right)$, and the accession ID at the Gene database of the National Center for Biotechnology Information (NCBI).

LPL: lipoprotein lipase, PPARG: peroxisome proliferator-activated receptor $\gamma, A L P L$ : alkaline phosphatase, tissue-nonspecific isozyme, $A C A N$ : aggrecan core protein, $B G N$ : byglican, COL2A1: collagen alpha-1(II) chain, COMP: cartilage oligomeric matrix protein, FMOD: fibromodulin, COL10A1: collagen alpha-1(X) chain, EEF1A1: expression analyses, elongation factor 1-alpha 1.

and reverse primer corresponding to a concentration of $5 \mu \mathrm{M}$ (Table 1), and $3 \mu \mathrm{L}$ MangoTaq polymerase (5,000 U/mL, Bioline $\mathrm{GmbH}$ ), and $1 \mu \mathrm{L}$ of cDNA in $21.9 \mu \mathrm{L}$ distilled water. The PCR was started by an initial denaturation step at $94^{\circ} \mathrm{C}$ for 3 minutes followed by cycles of denaturation at $94^{\circ} \mathrm{C}$ for 45 seconds, primer annealing for 45 seconds with primer specific temperatures as illustrated in Table 1 , and an elongation step at $72^{\circ} \mathrm{C}$ for 1 minute. Subsequent agarose gel electrophoresis was performed using $1.5 \%$ agarose gels (Merck) containing $0.5 \mu \mathrm{g} / \mathrm{L}$ ethidium bromide (AppliChem GmbH, Darmstadt, Germany) and 0.5×TBE buffer at $0.9 \mathrm{~V} / \mathrm{cm}$ of gel length. Gels were documented photographically using the Bio Profile software (LTF, Wasserburg, Germany) and analyzed densitometrically using the GelAnalyzer software (http://www.gelanalyzer.com). For all targeted gene expression analyses, elongation factor 1-alpha 1 (EEF1A1) was used as housekeeping gene.

\section{GAG Expression}

Pellets were digested using Papain (Sigma Aldrich $\mathrm{GmbH}$ ) for 24 hours and resulting solution was used to determine the GAG 
A

Immunohistochemical detection

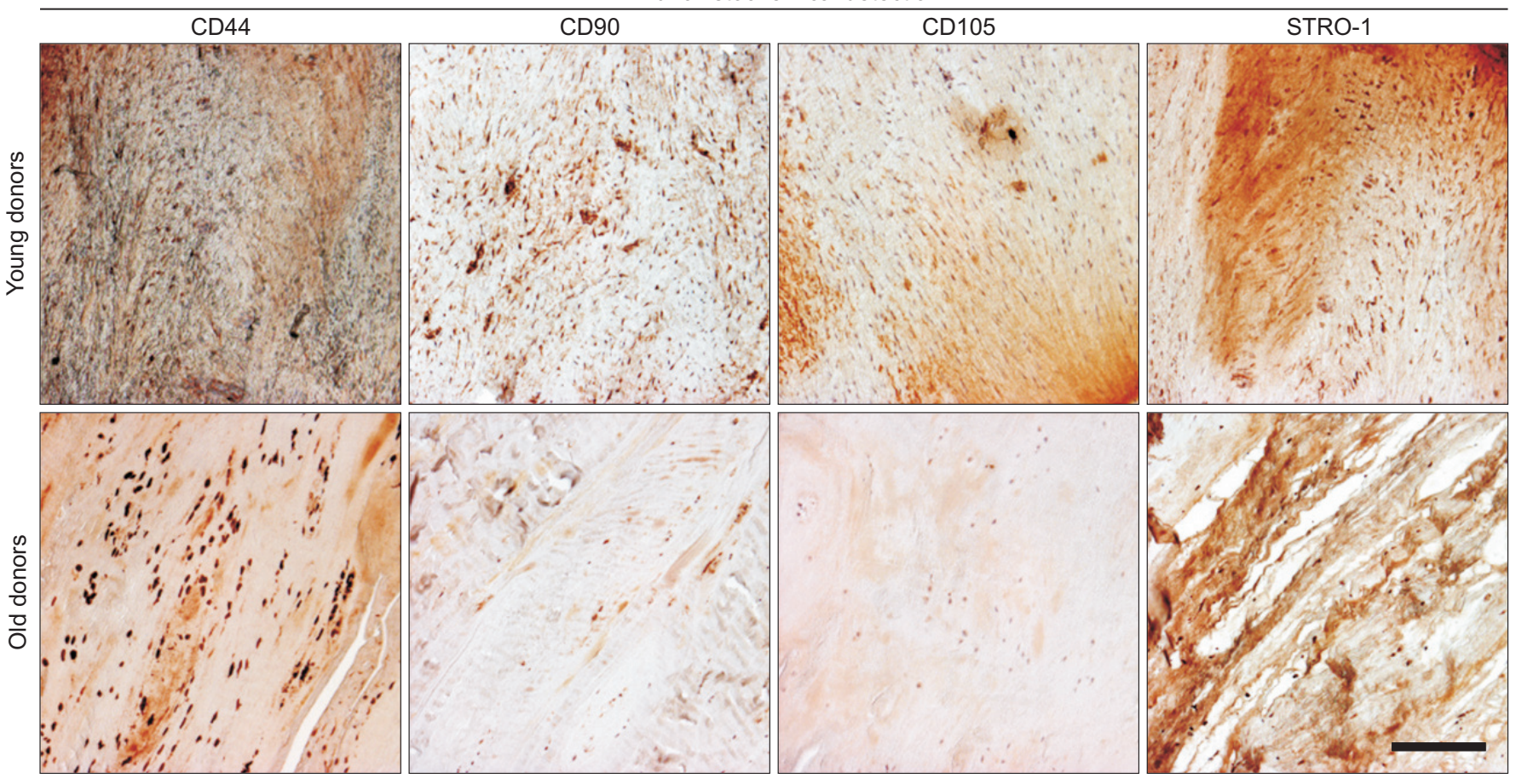

B

Histological assessment
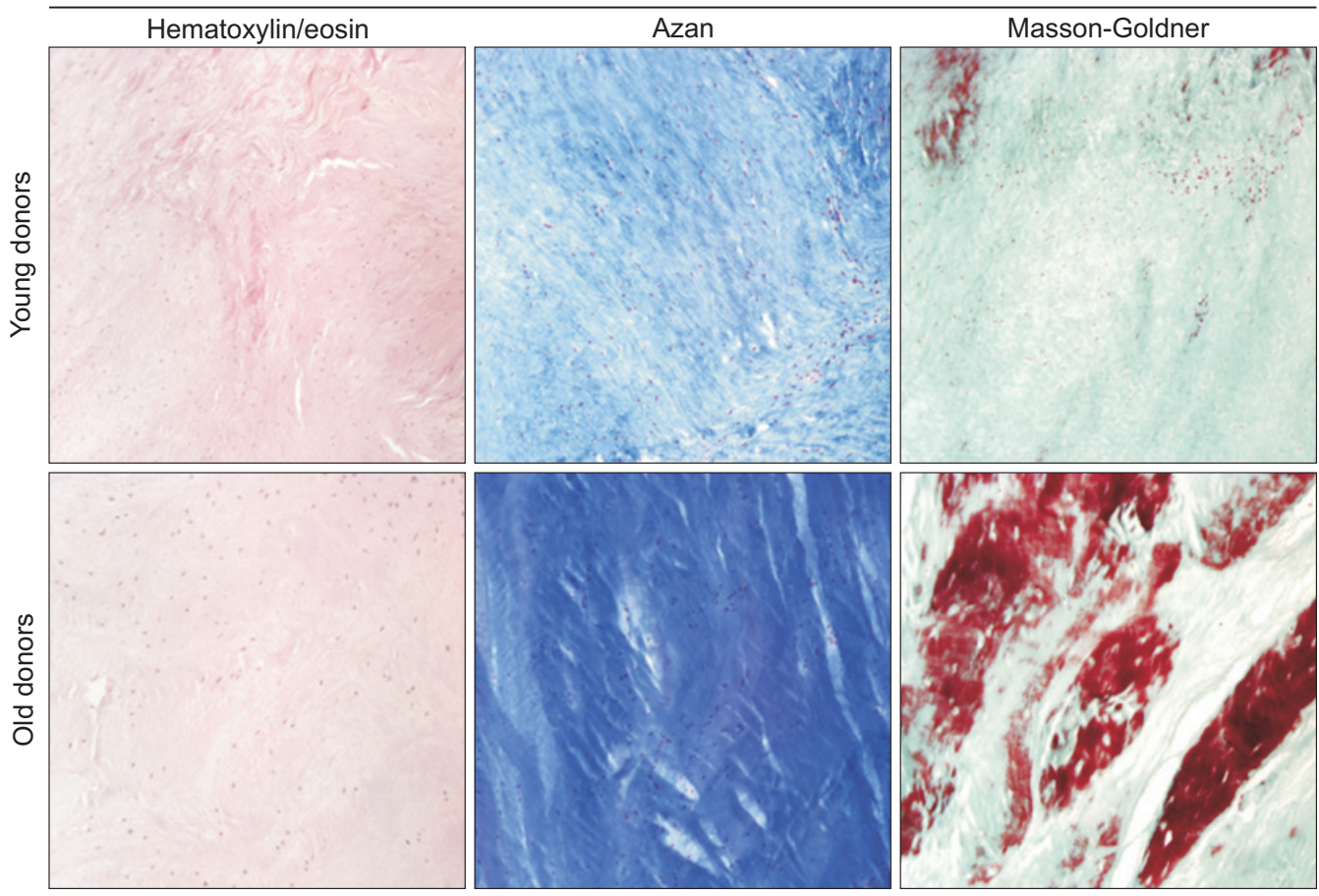

Fig. 1. Immunohistochemical and histological assessment of native anterior cruciate ligament (ACL) tissue. (A) The native ACL tissues from young and old donors were sectioned and investigated for the expression of the surface antigens CD44, CD90, CD105, and the STRO-1 antigen using immunohistochemistry. (B) Histological stainings for hematoxylin/eosin, azan, and Masson-Goldner were used to illustrate the cell and collagen distribution within the tissue specimens. Representative images are shown. 
content using the Blyscan Glycosaminoglycan Assay kit (Tebubio) according to the manufacturer's instructions. GAG content was normalized to the DNA content, which was determined using the Quant-iT dsDNA Broad-Range Assay Kit (Life Technologies $\mathrm{GmbH}$ ) following the manufacturer's protocol.

\section{Microchip Hybridization Experiments}

First passage cells were used for the analysis of transcriptomewide gene expression. Denaturing agarose gel electrophoresis and photometrical methods were used to ensure the messenger RNA (mRNA) quality. Synthesis of complementary DNA, microchip hybridization, and signal detection were performed using the Affymetrix GeneChipR 3'IVT express kit, the Affymetrix GeneChip expression analysis protocol ver. 2, the GeneChip scanner 3000 with the operating software GeneChip 1.2 (all Affymetrix). Using the comprehensive $\mathrm{R}$ based microarray analysis web frontend CARMAweb, the generated raw data were normalized by the guanine cytosine robust multi-array analysis (GCRMA) algorithm ${ }^{13,14}$. Afterwards, the values for the three biological replicates of each group were merged calculating the arithmetic mean for each probe followed by the determination of the relative fold change comparing the two age groups. Applying the moderated $t$ statistics included within the bioconductor package, linear models for microarray data (limma), and the Benjamini-Hochberg method for correction for multiple hypothesis testing, the statistical significance of the computed data was tested ${ }^{15,16)}$. The resulting list of probesets was filtered by discarding those that were not associated with a specific gene, had a fold change between 0.5 to 2.0 , or a $\mathrm{p}>0.05$. The remaining probesets and their corresponding genes were either grouped into positively or negatively regulated genes and used for pathway enrichment analysis using the gene ontology enrichment analysis and visualization tool Gorilla and the Gene Ontology (GO) Consortium's annotation and ontology toolkit AmiGO ${ }^{17,18}$. A list of all detectable genes was used as a background list. We filtered the resulting GO terms, and we discarded GO terms with less than 5\% differentially regulated genes or small GO terms being represented by $<3$.

\section{Statistical Analysis}

The Student $t$-test was utilized to test for significant differences in the CFU assay, the population doubling times, the histomorphometric analyses, densitometric RT-PCR analyses, GAG contents, DNA contents, and the ATP activities. p-values below 0.05 were considered statistically significant. Three independent samples from each group, each with technical triplicates, were used for all applicable assays; with exception to the CFU-f assay (young, $n=5$; old, $\mathrm{n}=6$ ) and cumulative population doubling (young, $\mathrm{n}=2$; old, $\mathrm{n}=4$ ).
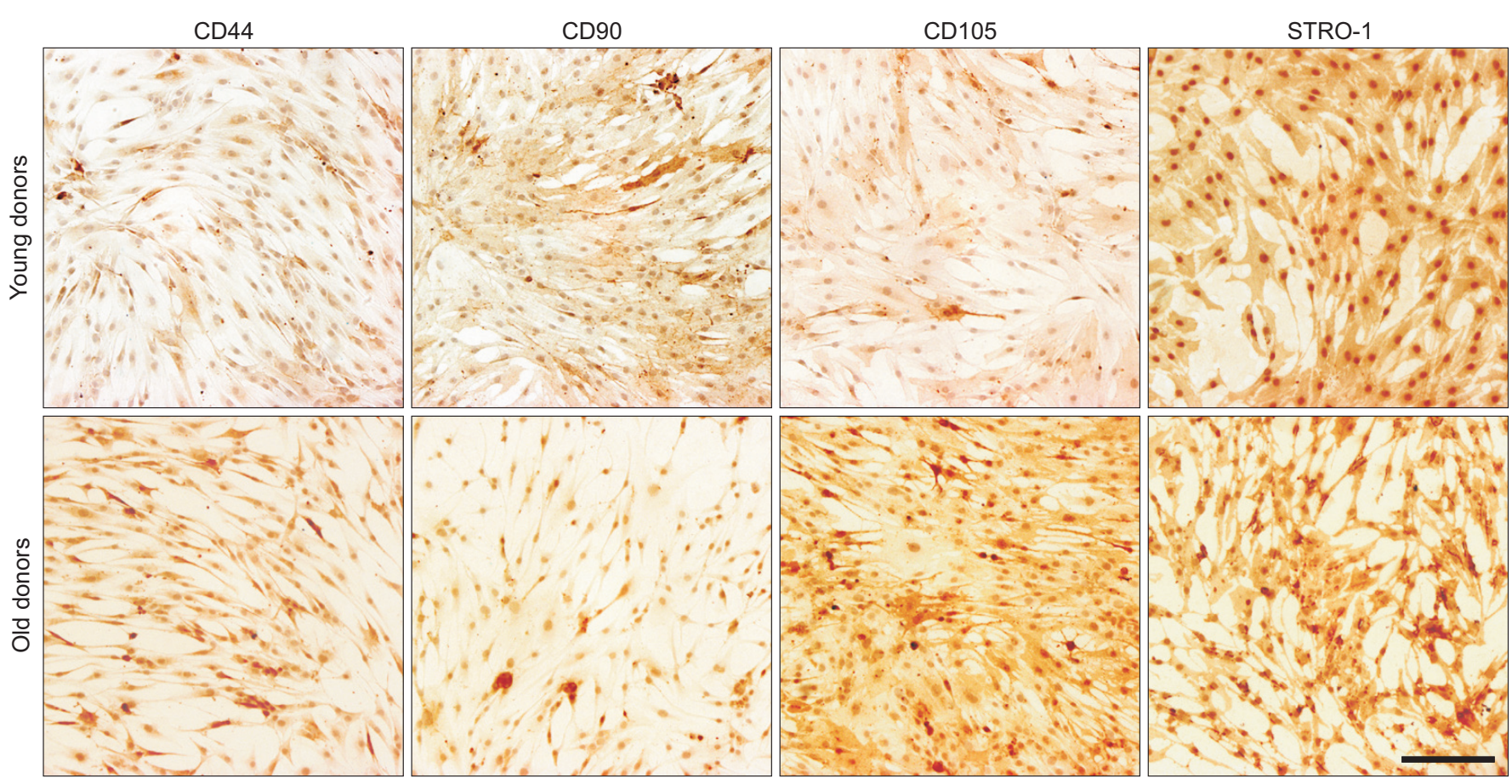

Fig. 2. Immunohistochemical detection of surface antigens on anterior cruciate ligament-derived mesenchymal stem cells (ACL-MSCs). Immunochemical detection showed positive signals for CD44, CD90, CD105, and the STRO-1 antigen on ACL-MSCs from young and old donors. Representative images are shown. 


\section{Results}

\section{ACL-MSCs from Young Donors Have a Greater Amount of Surface Antigens Characteristic for MSCs than ACL-MSCs from Old Donors}

Characterization of ACL-MSCs from young and old donors by tissue properties and surface antigens show differences in histological and immunohistochemical examinations (Figs. 1 and 2).

\section{The Transcriptome-Wide Analysis Reveals Differential} Gene Expression Patterns between ACL-MSCs from Young and Old Donors

Comparing ACL-MSCs from young and old donors, 561 probesets were found to be upregulated in the cells from young donors (Top 10 genes in Fig. 3A). The corresponding genes encompassed ECM molecules (such as COL1A1, COL5A1, COL6A1, and BGN amongst others) or growth factors (such as TGFB1) and enriched 16 terms in the GO biological process, 1 term in the GO biological function and 7 terms in the GO cellular component ontolo- gies (Fig. 3B). These terms were mainly associated with protein dephosphorylation and components of the cytoskeleton (Fig. 3B). Further, 613 probesets were upregulated in cells from old donors, when compared to young donors. The corresponding genes encompassed genes encoding for proteins that are involved in ossification processes (such as PDE1A, EREG, and SFRP1) or osteoarthritis (such as CTNNB1) and enriched 8 terms in the GO biological process and 3 terms in the GO biological function ontologies. Those were mainly related to nuclear transport, protein kinase B activity, epithelial-mesenchymal cell signaling, and the activity of RNA polymerase II cofactor (Fig. 3B).

\section{The Proliferative Capacity of ACL-MSCs Does Not Differ between Young and Old Donors}

The CFU-f frequency ranged from 0.005 to 0.3 with no distinct age-dependent distribution pattern being detectable (Fig. 4A). Similarly, no distinct age-dependent differences in the cumulative population doublings were observed. However, ACL-MSCs from two old donors entered growth arrest after approximately 80 days

\section{A}

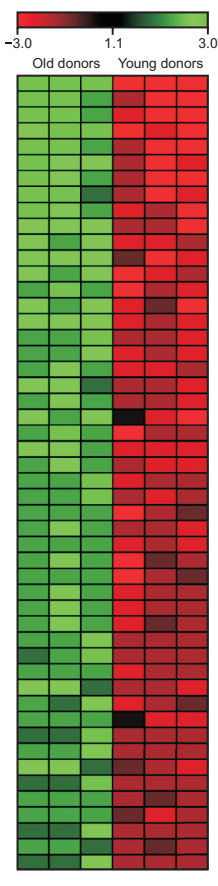

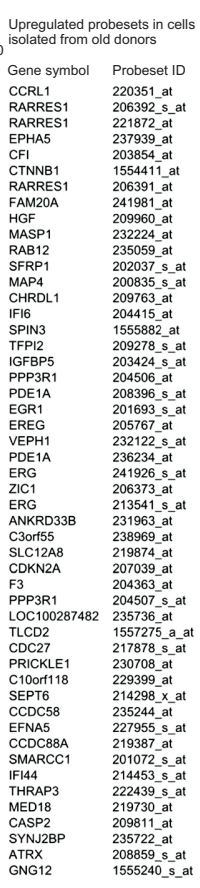

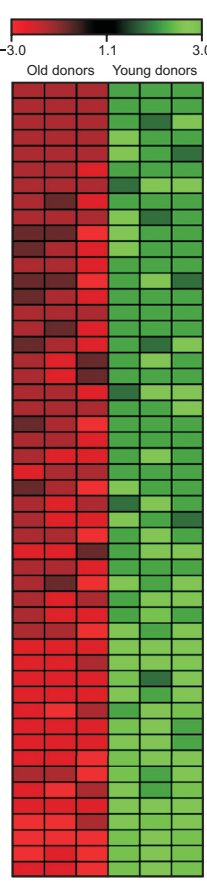

B

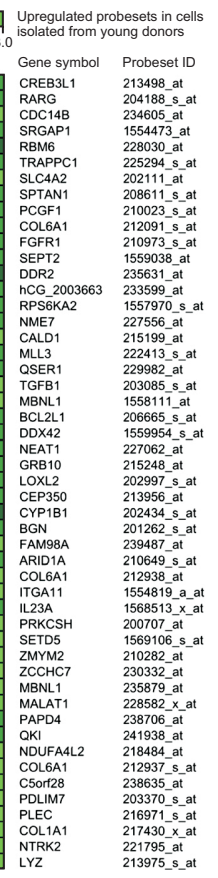

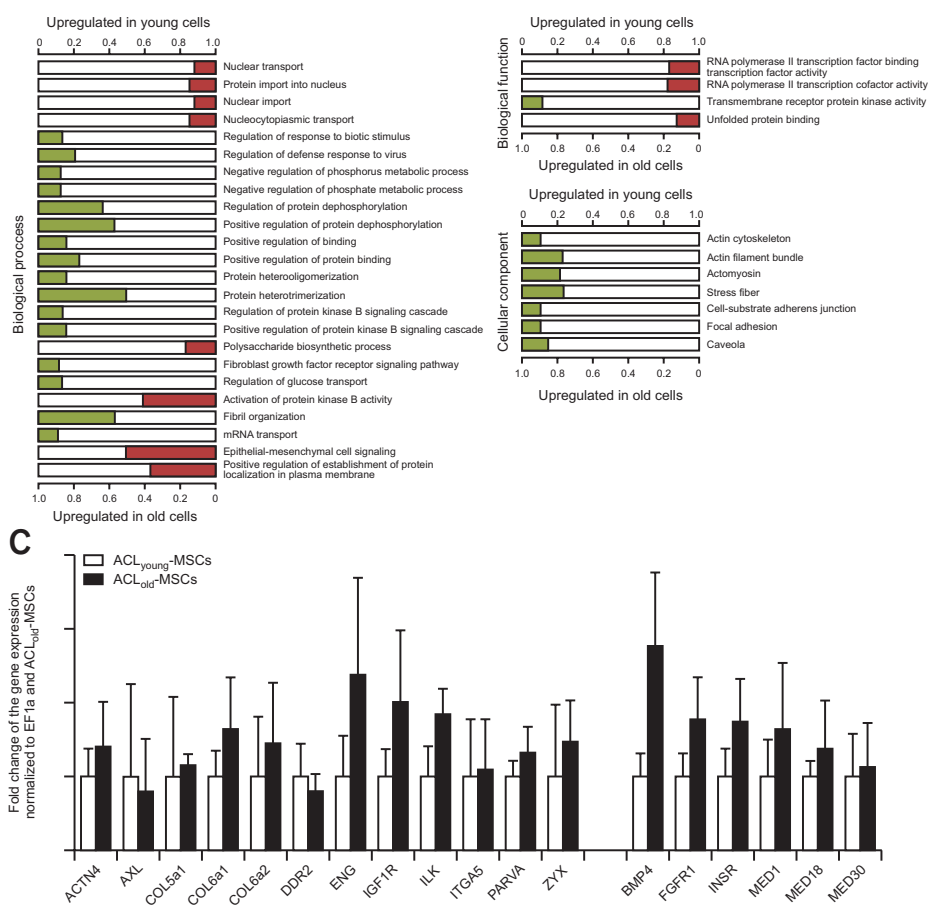

Fig. 3. Transcriptome-wide differential gene expression and pathway enrichment in the comparison of anterior cruciate ligament-mesenchymal stem cells (ACL-MSCs) from young and old donors. Using a microarray, 561 probesets were found to be upregulated in the cells from young donors, while 613 probesets were upregulated in cells from old donors. (A) The top 10 differentially expressed probesets are demonstrated as a heat map. (B) The corresponding genes enriched several terms in the GO biological process, biological function, and cellular component ontologies. Those enriched by the genes upregulated in ACL-MSCs from young donors mainly enriched pathways related to protein dephosphorylation and components of the cytoskeleton (B). Those enriched by the genes upregulated in ACL-MSCs from old donors were mainly related to nuclear transport, protein kinase B activity, epithelial-mesenchymal cell signaling, and the activity of RNA polymerase II cofactor. (C) Gene expression for BMP4 was higher in ACLMSCs from old donors than in ACL-MSCs from young donors. 

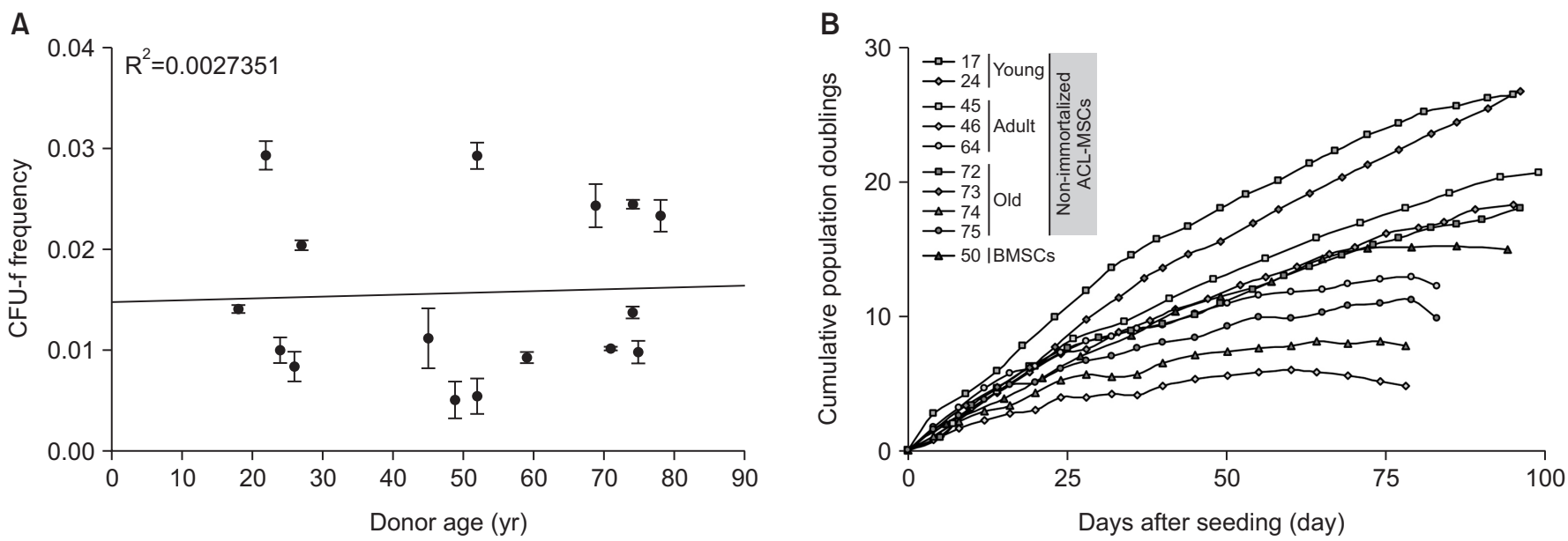

Fig. 4. Proliferative capacity of anterior cruciate ligament-mesenchymal stem cells (ACL-MSCs) from young and old donors. (A) The colony forming unit-fibroblast (CFU-f) frequencies of ACL-MSCs isolated from young $(n=5)$ and old donors $(n=6)$ were determined. No correlation with donor age was observed. (B) Cumulative population doublings for ACL-MSCs isolated from young $(\mathrm{n}=2)$ and old donors $(\mathrm{n}=4)$, as well as bone marrow-derived mesenchymal stem cells (BMSCs, $\mathrm{n}=1$ ), did not demonstrate significant differences between the groups. The dots represent mean values of technical triplicates.

in culture (Fig. 4B). When compared to BMSCs, ACL-MSCs of both groups did not show a distinct difference (Fig. 4B).

\section{ACL-MSCs from Young and Old Donors Do Not Differ in}

Their Potential for Chondrogenic Differentiation

ACL-MSCs from both age groups responded with a strong increase in alcian blue staining, when cultivated as pellets in the presence of TGF beta-1, comparable to BMSCs (Fig. 5AC). Likewise, the GAG content normalized to the DNA content increased in both ACL-MSC groups, when comparing induced versus control pellets. However, the normalized GAG content was generally higher in control and induced ACL-MSCs from young donors than in those obtained from old donors (Fig. 5D). All groups expressed the articular cartilage marker COL2A1, as well as the hypertrophy marker COL10A1 (Fig. 5E), resulting in the deposition of type II collagen in the superficial zones of the induced pellets (Fig. 5A). The staining intensity was highest in the ACL-MSCs from young donors, mildly reduced in ACLMSCs from old donors, and even further reduced in BMSCs. These differences were not substantial (Fig. 5A). In the analysis of proteoglycan expression, the upregulation of ACAN expression after chondrogenic induction was lower in the ACL-MSCs from old donors than in those from young donors or in BMSCs, but this finding did not reach the level of statistical significance $(\mathrm{p}>0.05)$. No difference in the upregulation of $B G N$ expression was observed (Fig. 5F).

\section{ACL-MSCs from Young and Old Donors Do Not Differ in} Their Potential for Osteogenic Differentiation

After osteogenic induction, ACL-MSCs from both age groups showed an increased ALP activity, comparable to BMSCs (Fig. $6 \mathrm{~A})$. Likewise, a strong production of mineralized ECM was detected, without any detectable difference between ACL-MSCs from young and old donors (Fig. 6A). Qualitatively, both ACLMSC groups produced less mineralized ECM than BMSCs (Fig. 6A). However, no significant difference was detected after histomorphometric quantification (Fig. 6D). On the level of mRNA expression, a strong increase in $A L P$ expression was detected in both ACL-MSCs from young and old donors (Fig. 6B). As BMSCs show a relatively high expression of $A L P$ in uninduced control cells (Fig. 6A and B), the increase in gene expression after osteogenic induction is smaller than the increase observed in both ACL-MSCs ( $p>0.05)$.

\section{ACL-MSCs from Young and Old Donors Do Not Differ in \\ Their Potential for Adipogenic Differentiation}

After adipogenic induction, ACL-MSCs from young and old donors synthesized lipid droplets (Fig. 7A). A slightly higher amount of lipid droplets was detected in ACL-MSCs from old donors when compared to young donors, but this effect was not considered significant ( $>0.05$ ) (Fig. 7B). Both ACL-MSC groups produced significantly less lipid droplets than the induced BMSCs. On the level of mRNA expression, the presence of adipogenic medium induced the expression of the adipocyte marker genes $L P L$ and PPARG in all groups (Fig. 7C). 
A

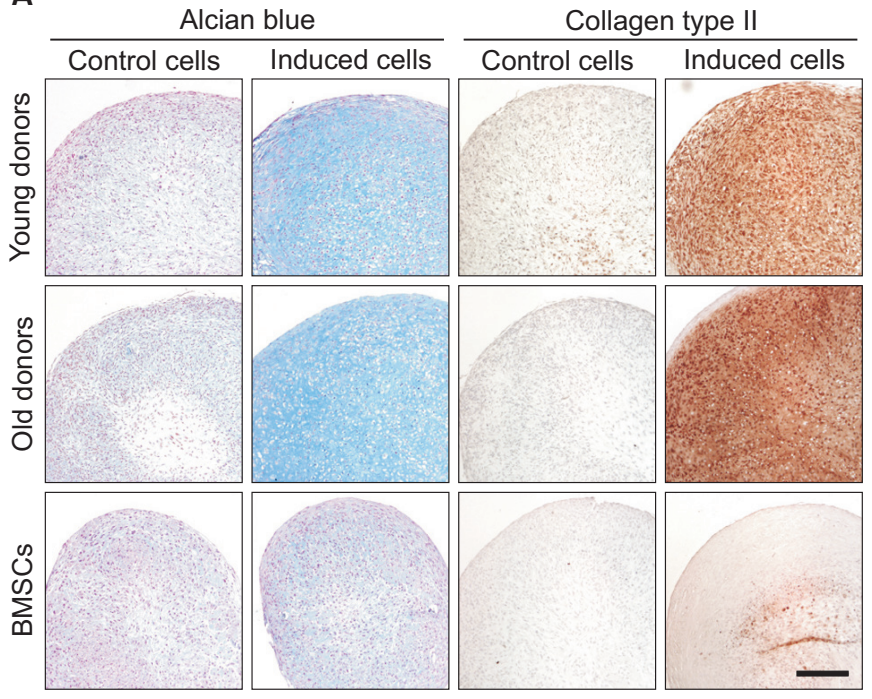

C

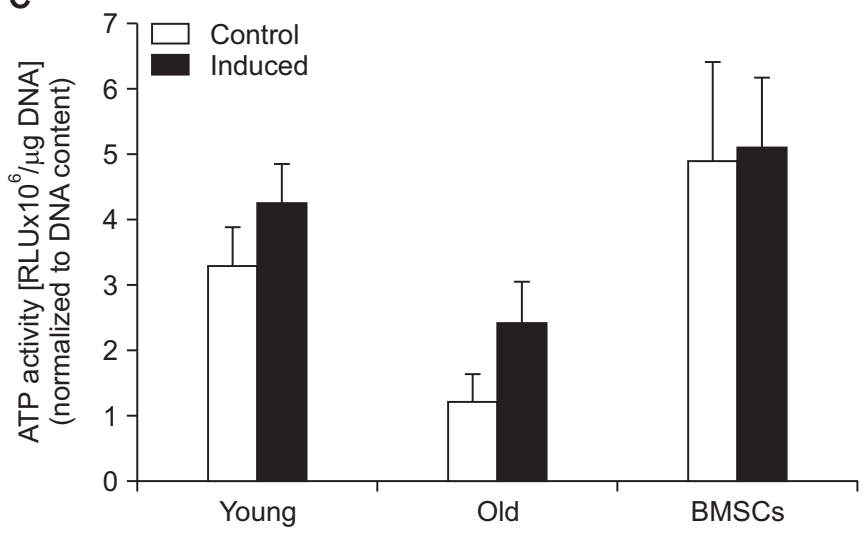

B

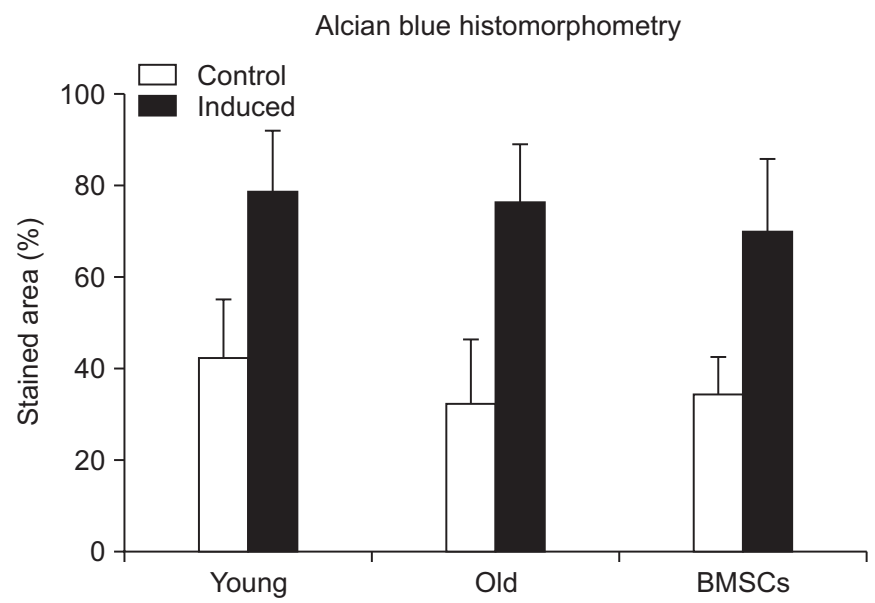

D

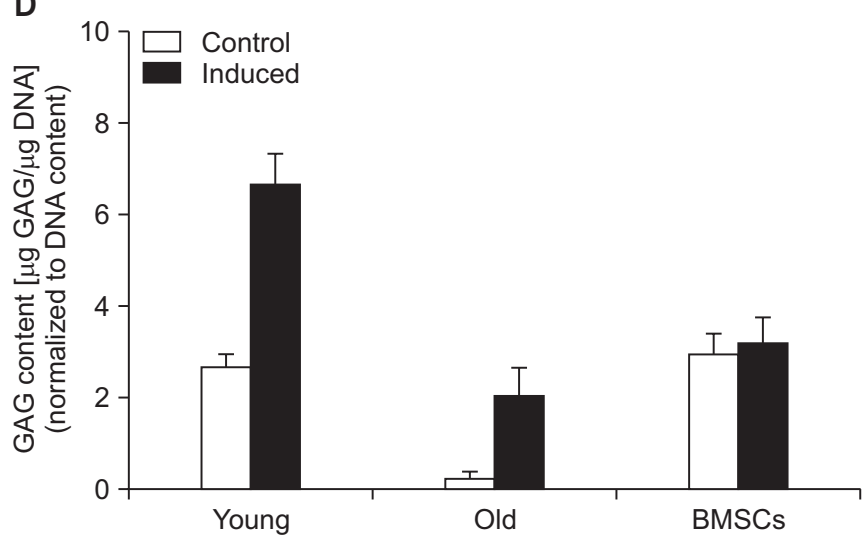

E

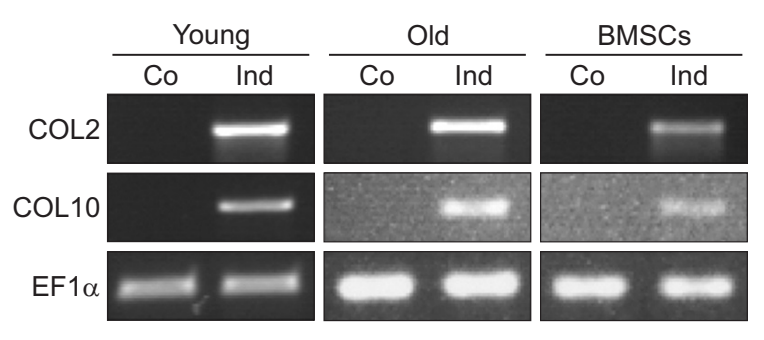

F

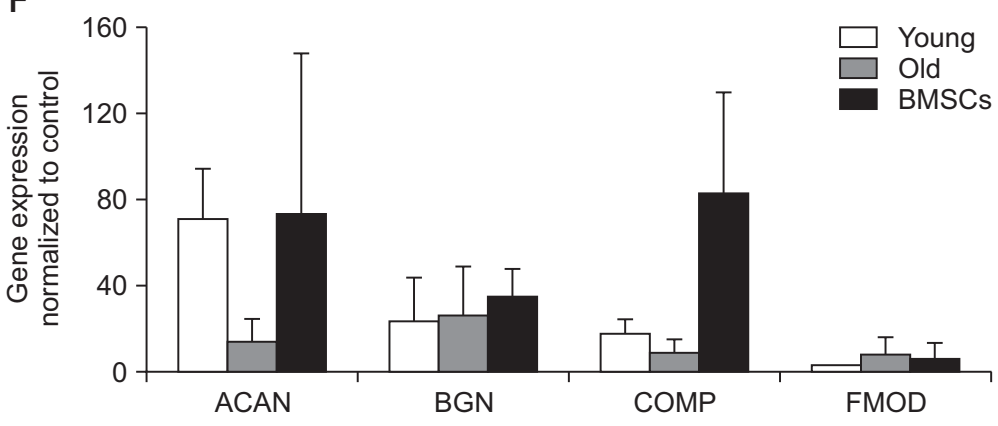

Fig. 5. Chondrogenic differentiation of anterior cruciate ligament-mesenchymal stem cells (ACL-MSCs) from young and old donors. (A-C) Increased glycosaminoglycan (GAG) staining was observed in cell pellets of all groups after induction of chondrogenic differentiation, which was quantified by histomorphometry. (D) Similarly, an increased GAG/DNA ratio was observed after induction in both ACL-MSCs from young and old donors. (E) Correspondingly, on the messenger RNA level, the expression of chondrocyte marker genes was increased in all groups after induction of chondrogenesis. (F) While the upregulation of ACAN expression was smaller in ACL-MSCs from old donors, this was not considered statistically significant. Upregulation of $B G N$ showed no difference. Bars represent mean values of $\mathrm{n}=3$ donors per group.

\section{Discussion}

The in vitro regenerative potential of ACL-MSCs from old do- nors did not substantially differ from that from young donors, suggesting that regenerative therapies of this intra-articular ligament are feasible in both age groups. Specifically, no significant 
A
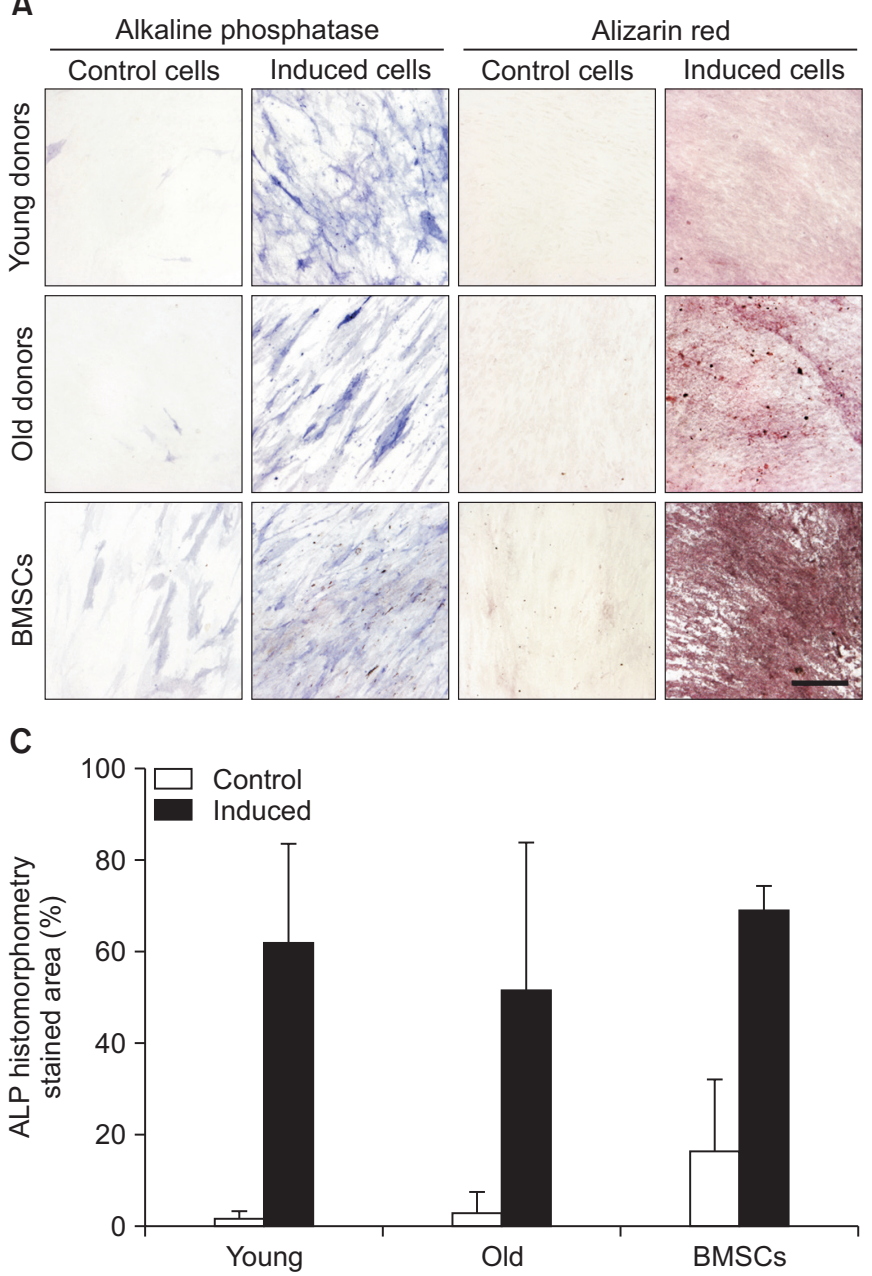

B

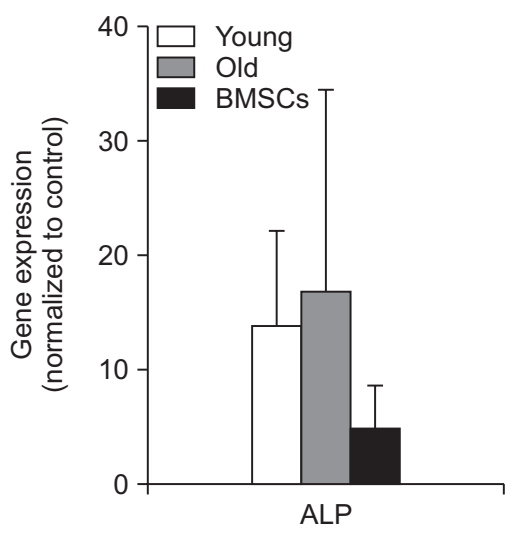

D

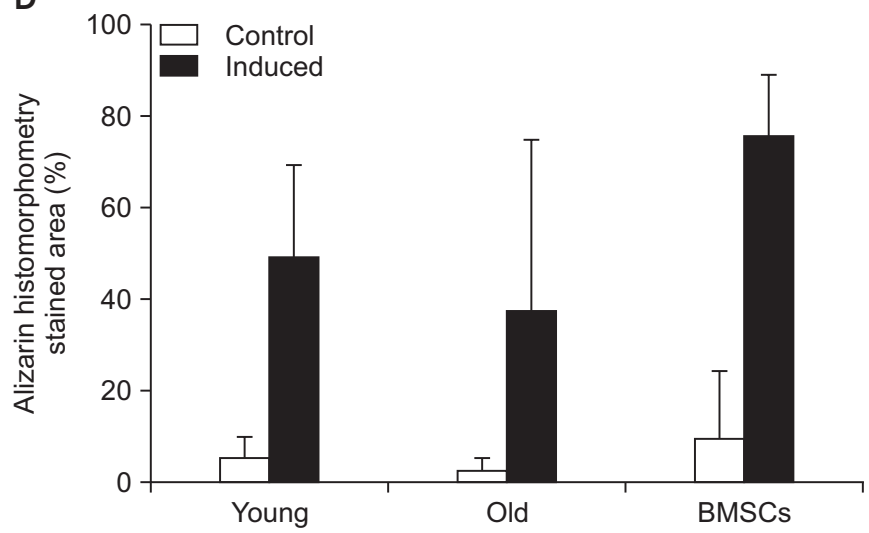

Fig. 6. Osteogenic differentiation of anterior cruciate ligament-mesenchymal stem cells (ACL-MSCs) from young and old donors. ACL-MSCs from both age groups showed an increased ALP activity and matrix mineralization (A) without significant differences between age groups or ACL-MSCs and bone marrow-derived mesenchymal stem cells (BMSCs) (C, D). A strong increase in ALP expression was detected in both ACL-MSCs from young and old donors, whereas the relative increase in BMSCs was lower due to the presumably high ALP expression in uninduced cells (B). Bars represent mean values of $\mathrm{n}=3$ donors per group.

differences in proliferative capacity (assessed using the CFU-f assay and cumulative population doubling times) and potential for multilineage differentiation (chondrogenic, osteogenic, and adipogenic lineage) were observed. However, in the transcriptomewide analysis of gene expression, the differential expression of several genes was detected in the comparison of ACL-MSCs from young and old donors, which enriched several pathways related to protein dephosphorylation, cytoskeleton, or protein kinase B activity. The different gene expression patterns in first passage ACL-MSCs of both age groups did not significantly impact the subsequently performed in vitro proliferation and multilineage differentiation.

We examined the age-dependent regenerative capacity of ACL-MSCs. The obtained results indicate that ACL-MSCs can be isolated from old donors (up to 79 years) with knee osteoarthritis and be used for regenerative therapies. A recent study also showed comparable phenotypes and multilineage potentials between ACL-MSCs derived from young and old donors, supporting our results ${ }^{17)}$. In contrast to our study, they found a greater proportion of MSCs in young patients than in older patients at initial isolation of MSCs, while in further cell passages, the proportions of MSCs from young and older patients were without differences in both studies ${ }^{17}$. This study supports our findings that ACL-MSCs from young and old donors have similar potentials for multilineage differentiation, but differences in gene expression could be detected, which might contribute to a different cytoskeleton and $\mathrm{ECM}^{17}$. In contrast to Lee et al. ${ }^{17)}$ and our presented study, Uefuji et al. ${ }^{19)}$ found not only a higher 
A

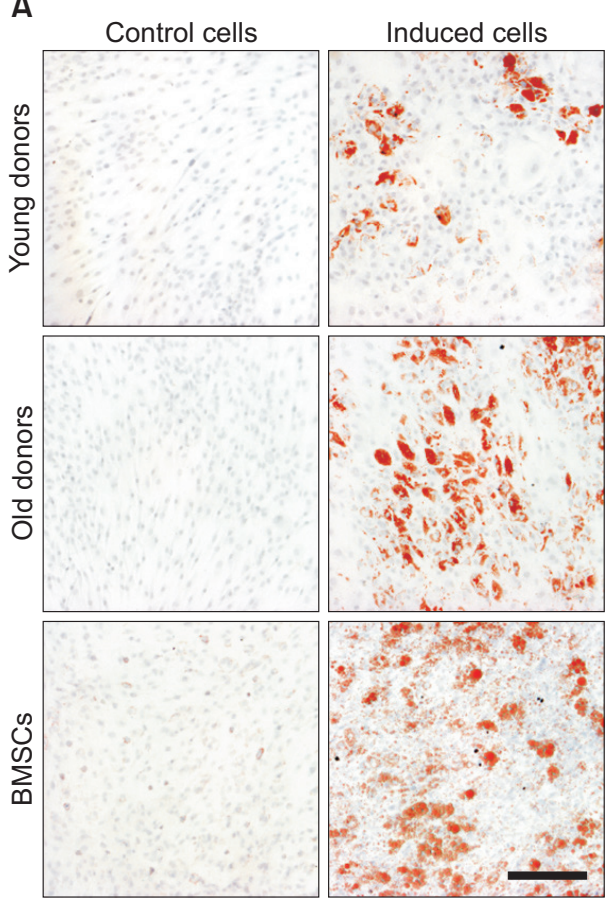

B

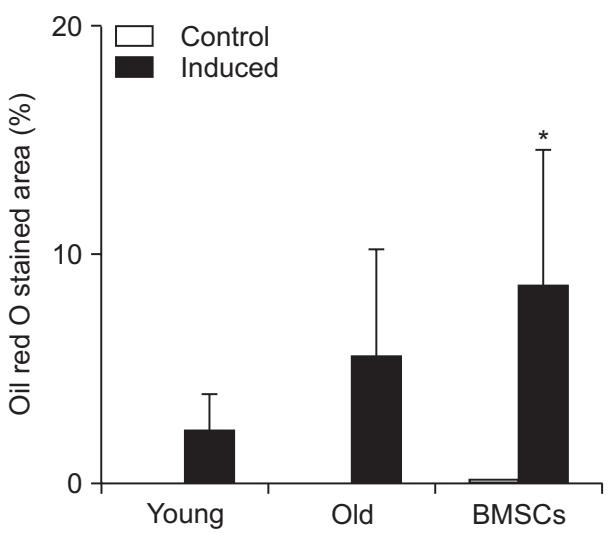

C

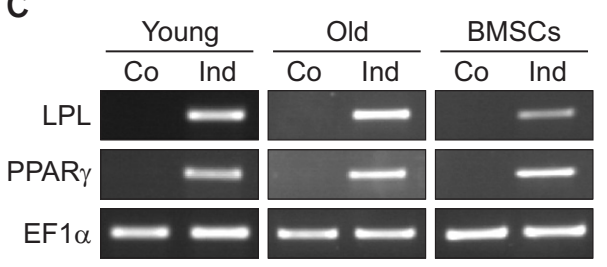

Fig. 7. (A) Adipogenic differentiation of anterior cruciate ligament-mesenchymal stem cells (ACL-MSCs) from young and old donors. (B) After adipogenic induction, a slightly higher increase in lipid production was detected in ACL-MSCs from old donors. When compared to young donors, this was not considered significant ( $p>0.05)$. Both ACL-MSC groups produced significantly less lipid droplets than the induced bone marrow-derived mesenchymal stem cells (BMSCs). (C) Adipogenic induction resulted in the expression of adipocyte marker genes in all groups. Bars represent mean values of $n=3$ donors per group. proportion of MSCs but also a higher potential for proliferation and multilineage differentiation of MSCs from young donors than MSCs from older donors in vitro. These findings might be important for native tissue healing potential in vivo, but as we and others showed, MSCs from older donors probably can be used for the development of regenerative therapies as MSCs from younger donors ${ }^{17)}$. However, our study has limitations. One such limitation is the use of in vitro assays, as it is currently not possible to define an effect size at which an observed difference would translate into a meaningful difference on in vivo application. It is likely that some of the slight differences observed here would reach the level of statistical significance when more independent samples were included. However, existing studies assessing tendon-derived MSCs, or BMSCs from healthy patients and patients with osteoarthritis did not document age-dependent differences in CFU-f frequencies either ${ }^{20,21}$. Other studies showed slight agedependent differences in CFU-f formation for BMSCs isolated from young and old donors, but none of them was statistically significant ${ }^{19,22)}$. Likewise, no significant age-dependent difference in the cumulative population doublings was observed, which is in accordance with some published characterizations of BMSCs ${ }^{23,24}$.

High donor variability for human BMSCs was demonstrated previously, suggesting that other patient-specific factors might influence the regenerative potential of MSCs to a greater extent than age ${ }^{25-27)}$. The present study cannot isolate age effects and the effects of acute ACL-injury and knee osteoarthritis, as all young donors were subject to knee injury and all old donors received a total knee replacement due to osteoarthritis. This might explain the findings of the transcriptome-wide gene expression analysis obtained in the present study. Higher expression of ligament ECM molecules in first passage ACL-MSCs (such as COL1A1, COL5A1, COL6A1, and BGN amongst others) or growth factors (such as TGF B1) was observed in young donors, while old donors demonstrated the upregulation of genes related to ossification (such as PDE1A, EREG, and SFRP1) and osteoarthritis (such as $C T N N B 1)^{28-30}$. In both conditions, older age and osteoarthritis, a lower regenerative capacity of ACL-MSCs would be expected in in vitro assays. The finding that ACL-MSCs obtained from young donors without a chronic joint disease are not substantially more potent than ACL-MSCs obtained from old donors with chronic osteoarthritis makes the conclusion of this study more versatile. ACL-MSCs can be derived from ligaments of young and acutely injured, as well as from old patients with chronic osteoarthritis and be used for regenerative therapies that require capacity to proliferate and the potential to differentiate along multiple mesenchymal lineages. However, future in vivo studies need to assess whether age-dependent differences can be detected in the respective application of ACL-MSCs.

\section{Conclusions}

In the conducted examinations, the regenerative potential of 
ACL-MSCs from old donors was not substantially lower than that from young donors, suggesting that the use of these cells for regenerative therapies is feasible in both age groups. These findings may be of considerable use for those developing regenerative therapies for the ACL or other knee joint tissues, which could be augmented with MSCs.

\section{Conflict of Interest}

No potential conflict of interest relevant to this article was reported.

\section{Acknowledgments}

We are grateful to Viola Zehe and Martina Regensburger for their excellent technical assistance.

\section{References}

1. Kim HS, Seon JK, Jo AR. Current trends in anterior cruciate ligament reconstruction. Knee Surg Relat Res. 2013;25:16573.

2. Frank C, Schachar N, Dittrich D. Natural history of healing in the repaired medial collateral ligament. J Orthop Res. 1983;1:179-88.

3. Murray MM, Martin SD, Martin TL, Spector M. Histological changes in the human anterior cruciate ligament after rupture. J Bone Joint Surg Am. 2000;82:1387-97.

4. Mihelic R, Jurdana H, Jotanovic Z, Madjarevic T, Tudor A. Long-term results of anterior cruciate ligament reconstruction: a comparison with non-operative treatment with a follow-up of 17-20 years. Int Orthop. 2011;35:1093-7.

5. Konrads C, Reppenhagen S, Plumhoff P, Hoberg M, Rudert $\mathrm{M}$, Barthel T. No significant difference in clinical outcome and knee stability between patellar tendon and semitendinosus tendon in anterior cruciate ligament reconstruction. Arch Orthop Trauma Surg. 2016;136:521-5.

6. Frobell RB, Roos HP, Roos EM, Roemer FW, Ranstam J, Lohmander LS. Treatment for acute anterior cruciate ligament tear: five year outcome of randomised trial. BMJ. 2013; 346:\{232.

7. Brophy RH, Gray BL, Nunley RM, Barrack RL, Clohisy JC. Total knee arthroplasty after previous knee surgery: expected interval and the effect on patient age. J Bone Joint Surg Am. 2014;96:801-5.

8. Huang TF, Chen YT, Yang TH, Chen LL, Chiou SH, Tsai
TH, Tsai CC, Chen MH, Ma HL, Hung SC. Isolation and characterization of mesenchymal stromal cells from human anterior cruciate ligament. Cytotherapy. 2008;10:806-14.

9. Steinert AF, Kunz M, Prager P, Barthel T, Jakob F, Noth U, Murray MM, Evans CH, Porter RM. Mesenchymal stem cell characteristics of human anterior cruciate ligament outgrowth cells. Tissue Eng Part A. 2011;17:1375-88.

10. Zhou S, Greenberger JS, Epperly MW, Goff JP, Adler C, Leboff MS, Glowacki J. Age-related intrinsic changes in human bone-marrow-derived mesenchymal stem cells and their differentiation to osteoblasts. Aging Cell. 2008;7:335-43.

11. Castro-Malaspina H, Gay RE, Resnick G, Kapoor N, Meyers P, Chiarieri D, McKenzie S, Broxmeyer HE, Moore MA. Characterization of human bone marrow fibroblast colonyforming cells (CFU-F) and their progeny. Blood. 1980;56: 289-301.

12. Pittenger MF, Mackay AM, Beck SC, Jaiswal RK, Douglas R, Mosca JD, Moorman MA, Simonetti DW, Craig S, Marshak DR. Multilineage potential of adult human mesenchymal stem cells. Science. 1999;284:143-7.

13. Rainer J, Sanchez-Cabo F, Stocker G, Sturn A, Trajanoski Z. CARMAweb: comprehensive R- and bioconductor-based web service for microarray data analysis. Nucleic Acids Res. 2006;34:W498-503.

14. Wu Z, Irizarry RA, Gentleman R, Martinez-Murillo F, Spencer F. A model-based background adjustment for oligonucleotide expression arrays. J Am Stat Assoc 2004;99:90917.

15. Smyth GK. Linear models and empirical bayes methods for assessing differential expression in microarray experiments. Stat Appl Genet Mol Biol. 2004;3:Article3.

16. Hochberg Y, Benjamini Y. More powerful procedures for multiple significance testing. Stat Med. 1990;9:811-8.

17. Lee DH, Ng J, Kim SB, Sonn CH, Lee KM, Han SB. Effect of donor age on the proportion of mesenchymal stem cells derived from anterior cruciate ligaments. PLoS One. 2015;10: e0117224.

18. Ashburner M, Ball CA, Blake JA, Botstein D, Butler H, Cherry JM, Davis AP, Dolinski K, Dwight SS, Eppig JT, Harris MA, Hill DP, Issel-Tarver L, Kasarskis A, Lewis S, Matese JC, Richardson JE, Ringwald M, Rubin GM, Sherlock G. Gene ontology: tool for the unification of biology: the Gene Ontology Consortium. Nat Genet. 2000;25:25-9.

19. Uefuji A, Matsumoto T, Matsushita T, Ueha T, Zhang S, Kurosaka M, Kuroda R. Age-related differences in anterior cruciate ligament remnant vascular-derived cells. Am J Sports 
Med. 2014;42:1478-86.

20. Kohler J, Popov C, Klotz B, Alberton P, Prall WC, Haasters F, Muller-Deubert S, Ebert R, Klein-Hitpass L, Jakob F, Schieker M, Docheva D. Uncovering the cellular and molecular changes in tendon stem/progenitor cells attributed to tendon aging and degeneration. Aging Cell. 2013;12:988-99.

21. Oreffo RO, Bennett A, Carr AJ, Triffitt JT. Patients with primary osteoarthritis show no change with ageing in the number of osteogenic precursors. Scand J Rheumatol. 1998; 27:415-24.

22. Stenderup K, Justesen J, Eriksen EF, Rattan SI, Kassem M. Number and proliferative capacity of osteogenic stem cells are maintained during aging and in patients with osteoporosis. J Bone Miner Res. 2001;16:1120-9.

23. Justesen J, Stenderup K, Eriksen EF, Kassem M. Maintenance of osteoblastic and adipocytic differentiation potential with age and osteoporosis in human marrow stromal cell cultures. Calcif Tissue Int. 2002;71:36-44.

24. Payne KA, Didiano DM, Chu CR. Donor sex and age influence the chondrogenic potential of human femoral bone marrow stem cells. Osteoarthritis Cartilage. 2010;18:705-13.

25. Bonab MM, Alimoghaddam K, Talebian F, Ghaffari SH, Ghavamzadeh A, Nikbin B. Aging of mesenchymal stem cell in vitro. BMC Cell Biol. 2006;7:14.

26. Fu W, Li Q, Tang X, Chen G, Zhang C, Li J. Mesenchymal stem cells reside in anterior cruciate ligament remnants in situ. Int Orthop. 2016;40:1523-30.

27. Kowalski TJ, Leong NL, Dar A, Wu L, Kabir N, Khan AZ, Eliasberg CD, Pedron A, Karayan A, Lee S, Di Pauli von Treuheim T, Jiacheng J, Wu BM, Evseenko D, McAllister DR, Petrigliano FA. Hypoxic culture conditions induce increased metabolic rate and collagen gene expression in ACL-derived cells. J Orthop Res. 2016;34:985-94.

28. Choi HD, Noh WC, Park JW, Lee JM, Suh JY. Analysis of gene expression during mineralization of cultured human periodontal ligament cells. J Periodontal Implant Sci. 2011; 41:30-43.

29. Du J, Ma Y, Ma P, Wang S, Fan Z. Demethylation of epiregulin gene by histone demethylase FBXL11 and BCL6 corepressor inhibits osteo/dentinogenic differentiation. Stem Cells. 2013;31:126-36.

30. Pasold J, Osterberg A, Peters K, Taipaleenmaki H, Saamanen AM, Vollmar B, Muller-Hilke B. Reduced expression of Sfrp1 during chondrogenesis and in articular chondrocytes correlates with osteoarthritis in STR/ort mice. Exp Cell Res. 2013;319:649-59. 